\title{
NUEVAS APROXIMACIONES AL ARTE RUPESTRE DE FUEGO-PATAGONIA, CHILE: CARACTERIZACIÓN Y COMPARACIÓN DE LOS SITIOS DEL CONTINENTE Y DE LOS CANALES DEL EXTREMO SUR
}

CAMILA MUÑOZ S.a

\section{RESUMEN}

En este trabajo se presentan los resultados obtenidos a partir del registro de siete sitios con arte rupestre de Patagonia meridional, Chile: cuatro en el sector del continente y tres en los canales, a los cuales se integraron los datos de 44 yacimientos publicados en diferentes fuentes bibliográficas. A partir del análisis cuantitativo y estadístico realizado a través de tres unidades diferentes compuestas por el motivo (micro), el conjunto o panel (meso) y el sitio (macro), se busca ahondar, por primera vez, en la comparación de los contextos de los canales y el continente de la región de Magallanes, para dar luces respecto al posible intercambio de información y códigos visuales entre los distintos grupos que habitaron dicha región.

PALABRAS CLAVE: arte rupestre, Patagonia continental, canales, intercambio de información, códigos visuales.

\section{NEW APPROACHES TO THE ROCK ART OF FUEGO-PATAGONIA, CHILE: CHARACTERIZATION AND COMPARISON OF THE SITES IN THE CONTINENT AND THE CHANNELS OF EXTREME SOUTH}

\begin{abstract}
This work presents the results obtained from seven rock art sites from the area of Southern Patagonia, Chile: four in the continent and three in the channels, to which the data of 44 deposits from different bibliographical sources were integrated. Based on the quantitative and statistical analysis carried out on three different scales composed by the motif (micro), the panel (meso) and the site (macro), the aim is to deepen, for the first time, the comparison of the contexts from the channels and the continent of the Magallanes region, in order to understand the possible information exchange and visual codes between the different groups that inhabited that region.
\end{abstract}

KEY WORDS: Rock Art, Continental Patagonia, Channels, Information Exchange, Visual Codes.

a École Doctorale 112 Université Paris 1 Panthéon-Sorbonne, Laboratoire d'Ethnologie Préhistorique UMR 7041 ArScAN. 36 rue des Bergers, 75015, París, Francia. $\$ camila.munoz.soto@gmail.com 


\section{INTRODUCCIÓN}

La zona denominada como Fuego-Patagonia comprende una vasta extensión de territorio compartida entre Chile y Argentina, que en su porción chilena se caracteriza por la presencia de cuatro geomorfologías que dan forma a esta gran masa de mar y tierra (Pisano, 1977), identificadas como los archipiélagos Patagónicos, la cordillera Andino-Patagónica, la precordillera oriental y la estepa. Esto permite la conformación de variados paisajes con recursos diferenciados, los cuales fueron aprovechados por los grupos que se asentaron tanto en el continente como en los canales hace 12.000 y 7.000 años AP respectivamente (Ortiz-Troncoso, 1975; Orquera \& Piana, 1986-1987; Massone, 1987; Bird, 1988; Nami \& Menegaz, 1991; Prieto, 1991; Nami \& Nakamura, 1995; Massone \& Prieto, 2004; San Román, 2005, 2016; Morello et al. 2012; Legoupil, 2013; Martin, 2013; Martin et al. 2015). Estos grupos elaboraron diversos motivos rupestres tanto en aleros, paredones y cuevas.

Los primeros estudios en relación al arte rupestre se remontan a los trabajos realizados en la década de 1970 por Felipe Bate (1970, 1971), quien hizo la primera descripción de las pinturas de las áreas de Torres del Paine, Lago Sofía y Campo Volcánico de Pali Aike. Dichos estudios permitieron el establecimiento del denominado Estilo Río Chico (Pali Aike), caracterizado por trazos lineales cortos y acoplados, series de trazos lineales de un solo color, series de líneas paralelas en rojo y negro atravesadas por una línea perpendicular, signos complejos, figuras antropomorfas y zoomorfas esquemáticas de pequeño tamaño. Este estilo fue considerado como un sub-grupo dentro de la categoría de Símbolos Complejos planteada por Menghin (1952, 1957), y asociada al período III de Bird (1988), otorgándole una cronología tardía.

Por otro lado, Bate (1970) definió otra modalidad estilística para el área de Torres del Paine, nombrada como Lago Sarmiento, la cual se hallaba compuesta prácticamente en su totalidad por antropomorfos y zoomorfos de gran tamaño, además de algunos motivos geométricos realizados a partir de trazos gruesos y el relleno interno de las figuras. También estableció un grupo para los sitios identificados en el área de Lago Sofía, caracterizados por grandes motivos a base de puntos, tridígitos e hileras de puntos que se combinaban con geométricos simples.

Posteriormente, durante la década de 1980 Mauricio Massone (1982) retoma los trabajos iniciados por Bate, a partir del nuevo registro de sitios tanto en Pali Aike como en cerro Benítez y lago Sofía. El estudio del material lítico en superficie, además de la excavación del sitio Dos Herraduras donde se obtiene una fecha de 2.870 \pm 65 años AP en asociación con las pinturas, apoyan la hipótesis respecto a la cronología tardía de las representaciones. Sin embargo, los estudios cesarían hasta el nuevo milenio, cuando Francisco Gallardo (2009) y Marcela Sepúlveda (2011) realizan los primeros trabajos arqueométricos sobre los pigmentos utilizados en las pinturas.

En cuanto a los canales, el primer registro de arte rupestre se realiza en la década de 1990 en el fiordo de Última Esperanza (Legoupil \& Prieto, 1991), específicamente en el sitio Cueva de los Niños, donde fue identificada una serie de manchas rojas. Posteriormente, durante las dos primeras décadas del 2000, se efectuó el descubrimiento de los sitios Grotte du Pacifique y Cueva Augusta 1 en el archipiélago Madre de Dios (Fage, 2006; Jaillet et al. 2009, 2010), los cuales fueron asociados a una fecha de 3.000-4.000 años AP (Maire et al. 2009). Por otra parte, en el área comprendida entre canal Beagle y cabo de Hornos, se identificaron los sitios Alero Martín González Calderón (González et al. 2014) y Alero Picton 1 (Muñoz et al. 2016), lo que permitió confirmar la presencia de este tipo de representación en los canales australes. Sin embargo, dichos estudios se abocaron a la descripción de los motivos presentes en los yacimientos, lo que hace necesaria una primera aproximación comparativa de los contextos de los canales y el continente. Es por esto que el objetivo de este trabajo recae en realizar una primera comparación del arte rupestre en estos dos sectores, para definir si hubo intercambio y/o circulación de información a partir de códigos visuales, debido a que se considera al arte rupestre como un proceso adaptativo que facilita y resguarda la comunicación (McDonald \& Veth, 2011; Cordero et al. 2019; Acevedo \& Fiore, 2020), a través del cual se expresan mensajes y se intercambia información (Wobst, 1977; Wiessner, 1983, 1985; Barton et al. 1994; Domingo Sanz, 2005). 


\section{METODOLOGÍA DE ESTUDIO}

Para llevar a cabo la investigación se trabajó a partir de tres tipos de fuentes, considerando el grado de información disponible para los sitios (Muñoz, 2019). Es así como se comenzó con los datos relevados directamente en terreno a partir de campañas de estudio realizadas en 2016 y 2018 , las cuales abarcaron cuatro sitios en el continente: Dos Herraduras, Lago Sofía, Cerro Benítez 11 y Lago Sarmiento $1, y$ un yacimiento en los canales: Alero Picton 1. Posteriormente, dos sitios en los canales fueron trabajados a partir del registro fotográfico realizado en 2018 por el antropólogo Nelson Aguilera: Grotte du Pacifique y Cueva Augusta 1. Finalmente, toda la información fue comparada con los datos bibliográficos disponibles de 44 sitios con arte rupestre de Patagonia meridional (Bate, 1970, 1971; Molina, 1972; Massone, 1982; Legoupil \& Prieto, 1991; Campan et al. 2007; Gallardo, 2009; Sepúlveda, 2011; Manzi \& Carballo Marina, 2012; Charlín, 2014; González et al. 2014). Esto dio un total de 51 sitios $^{1}$ distribuidos en seis áreas distintas (Fig. 1 y Tabla 1). Esta información fue tratada a partir de tres unidades de análisis, tomando como ejemplo las investigaciones anteriormente realizadas en otras zonas de Patagonia (Re et al. 2009; Acevedo et al. 2013, 2014; Fiore, 2016): micro, meso y macro.

La unidad micro se centró en el tipo de motivo, coloración y técnica de realización. En el tipo de motivo se efectuó una gran subdivisión entre figurativos y no figurativos. En el primer grupo se incluyeron las improntas de mano tanto

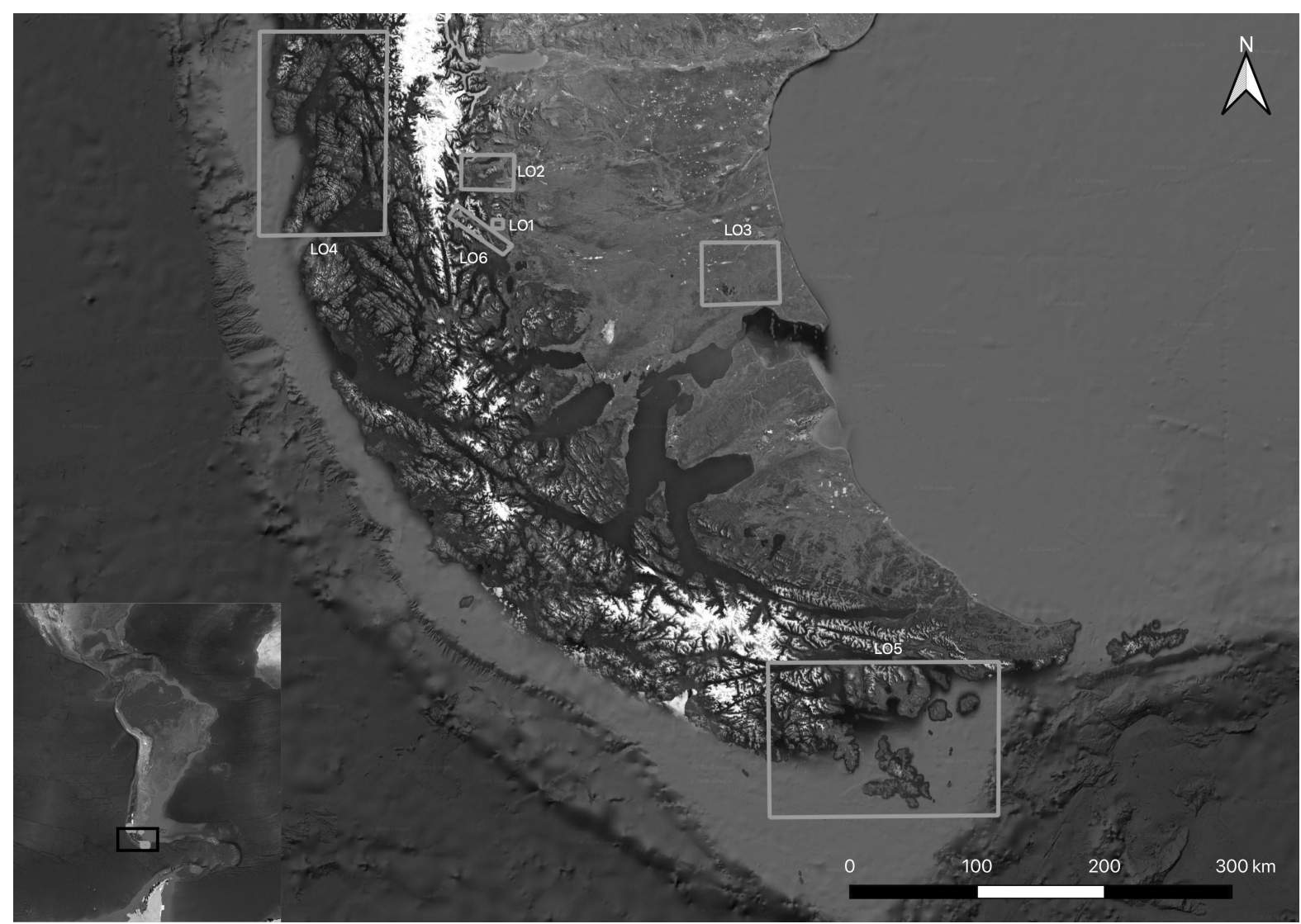

Fig. 1. Mapa en donde se presentan las seis áreas de estudio: LO1 cerro Benítez/lago Sofía, LO2 Torres del Paine, LO3 Campo Volcánico de Pali Aike/río Gallegos, LO4 archipiélago Madre de Dios, LO5 canal Beagle/cabo de Hornos y LO6 fiordo de Última Esperanza.

1 Para el área de Campo Volcánico de Pali Aike se incluyeron también los sitios identificados en la vertiente argentina, además de aquellos presentes en río Gallegos. 
Tabla 1. Sitios analizados por sectores y áreas, cantidad de motivos, colores y técnicas utilizadas.

*En el apartado número de motivos sólo se consideraron aquellos registrados a partir de los trabajos en terreno y fotografías.

"Los colores y técnicas incluyen las descritas en fuentes bibliográficas.

\begin{tabular}{|c|c|c|c|c|c|c|c|}
\hline Sector & Área & $\begin{array}{c}\text { Número total } \\
\text { de sitios }\end{array}$ & $\begin{array}{l}\text { Número } \\
\text { de sitios } \\
\text { registrados }\end{array}$ & $\begin{array}{c}\text { Número } \\
\text { de sitios en } \\
\text { bibliografía }\end{array}$ & $\begin{array}{l}\text { Número de } \\
\text { motivos }\end{array}$ & Color ${ }^{2 *}$ & Técnica** \\
\hline \multirow{3}{*}{ Continente } & $\begin{array}{c}\text { LO1 } \\
\text { Cerro Benítez/ } \\
\text { lago Sofía }\end{array}$ & 9 & 3 & 6 & 35 & $\begin{array}{c}\text { Rojo, rojo- } \\
\text { anaranjado, } \\
\text { marrón } \\
\text { oscuro, blanco }\end{array}$ & $\begin{array}{l}\text { Pintura plana, } \\
\text { lineal, a base de } \\
\text { puntos, positivo }\end{array}$ \\
\hline & $\begin{array}{l}\text { LO2 } \\
\text { Torres del } \\
\text { Paine }\end{array}$ & 2 & 1 & 1 & 44 & $\begin{array}{c}\text { Rojo, rojo- } \\
\text { anaranjado, } \\
\text { blanco }\end{array}$ & $\begin{array}{c}\text { Pintura plana, } \\
\text { lineal, a base de } \\
\text { puntos, negativo, } \\
\text { positivo }\end{array}$ \\
\hline & $\begin{array}{c}\text { LO3 } \\
\text { Campo } \\
\text { Volcánico de } \\
\text { Pali Aike/río } \\
\text { Gallegos }\end{array}$ & 35 & - & 35 & - & $\begin{array}{c}\text { Rojo, rojo } \\
\text { oscuro, rojo } \\
\text { carmesí, } \\
\text { amarillo, } \\
\text { blanco, negro }\end{array}$ & $\begin{array}{l}\text { Pintura plana, a } \\
\text { base de puntos, } \\
\text { estarcido, } \\
\text { negativo, positivo }\end{array}$ \\
\hline \multirow{4}{*}{ Canales } & $\begin{array}{c}\text { LO4 } \\
\text { archipiélago } \\
\text { Madre de Dios }\end{array}$ & 2 & 2 & - & 78 & $\begin{array}{c}\text { Rojo, rojo- } \\
\text { anaranjado, } \\
\text { negro }\end{array}$ & $\begin{array}{l}\text { Pintura plana, } \\
\text { lineal, a base de } \\
\text { puntos, estarcido }\end{array}$ \\
\hline & $\begin{array}{c}\text { LO5 } \\
\text { canal Beagle/ } \\
\text { cabo de } \\
\text { Hornos }\end{array}$ & 2 & 1 & 1 & 5 & Rojo, blanco & $\begin{array}{l}\text { Pintura plana, } \\
\text { lineal }\end{array}$ \\
\hline & LO6 & & & & & & \\
\hline & $\begin{array}{l}\text { fiordo de } \\
\text { Última } \\
\text { Esperanza }\end{array}$ & 1 & - & 1 & - & Rojo & Estarcido \\
\hline \multicolumn{2}{|c|}{ Total } & 51 & 7 & 44 & 162 & - & - \\
\hline
\end{tabular}

en negativo como en positivo, antropomorfos, zoomorfos y huellas de animal (tridígito). Los no figurativos fueron los tradicionalmente designados como geométricos. Para una mejor representación de los datos en los posteriores análisis estadísticos se decidió concentrar diversos tipos. Por ejemplo, la categoría línea incluyó las agrupaciones y los trazos aislados. En resumen, se establecieron 20 atributos en donde se incluyeron las manchas.

En cuanto a los colores de las representaciones, se registraron ocho clases: rojo, rojo oscuro, rojo-anaranjado, rojo carmesí, amarillo, marrón oscuro, negro y blanco. En relación a la técnica empleada, debido a que no se efectuó un análisis detallado en terreno de dicha variable que permitiera inferir el tipo de herramienta utilizada, se establecieron seis grandes categorías: pintura plana, a base de puntos, lineal, negativo, positivo y estarcido (salpicadura de pintura).

En cuanto a la unidad meso, se centró en el panel o conjunto, entendido como una asociación visual que permite identificar a distintos motivos como una parte de una unidad, ya sea por una lógica de elaboración o por una lógica visual (Artigas \& Muñoz, 2015, p. 508). De esta forma, se dio especial relevancia a la asociación entre motivos, por lo que se contó con tres atributos consistentes en la yuxtaposición, es decir, cuando la distancia entre dos motivos es inferior o igual al largo máximo de la figura más grande (LeroiGourhan, 1980); la superposición, entendida 
como el emplazamiento de un motivo sobre otro, y el motivo aislado. Por último, la unidad macro se centró en el sitio, por lo que se contó con las variables tipo de sitio, dividida en cueva, alero, paredón y roca aislada; las dimensiones (largo, ancho); orientación y altitud.

Debido al grado diferenciado de información que presentaban los yacimientos, se decidió enfocar el análisis en la unidad micro, agrupando un total de 162 representaciones obtenidas por el registro directo de los motivos, las que fueron tratadas a partir del programa DStretch (Harman, 2008) para su mejor identificación. Estos datos fueron sometidos a un Análisis Factorial de Correspondencia (AFC), que permitió el establecimiento de tipologías y asociaciones, y a una Clasificación Jerárquica Ascendente (CAH). El resto de las unidades sólo fue analizado de forma cuantitativa.

El AFC es una técnica estadística que permite dar una representación gráfica a un gran número de datos, para determinar los agrupamientos $y$ oposiciones entre distintas variables y los atributos que las representan (Cibois, 2006, 2007), de acuerdo a distintos planos o combinaciones lineales de factores o variables y sus atributos. Estos son representados a partir de ejes; uno que separa la muestra verticalmente y otro que la divide horizontalmente. Por consiguiente, sólo se consideran aquellos planos que acumulen la mayor cantidad de información, es decir, todos aquellos que superen el $5 \%$.

En resumidas cuentas, se trabajó en base a la presencia/ausencia de atributos para cada representación registrada, considerando las variables anteriormente expuestas, además de agregar una última categoría denominada como localidad (área), con la finalidad de identificar dónde se encontraba emplazado cada motivo. Fue así como se definieron cuatro áreas: LO1 cerro Benítez/lago Sofía, LO2 Torres del Paine, LO4 archipiélago Madre de Dios y LO5 canal Beagle/ cabo de Hornos. Al unir los resultados con la información bibliográfica se incluyeron dos nuevas áreas: LO3 Campo Volcánico de Pali Aike/río Gallegos y LO6 fiordo de Última Esperanza. El AFC fue trabajado a partir del programa estadístico Module Stat 2, donde cada motivo fue designado con una letra según el sitio al que pertenecía, seguido por un número correlativo. Los atributos fueron nombrados por sus primeras tres letras (ej.: zoomorfo se denominó como zoo).

En cuanto a la Clasificación Jerárquica Ascendente, corresponde a una herramienta que permite dividir la población (variables y atributos) en diferentes clases o sub-grupos en función de su afinidad (Lamassé et al. 2019), para representar de mejor forma las asociaciones, en base a criterios previamente definidos por el investigador y las agrupaciones dadas por el AFC.

\section{RESULTADOS Y ANÁLISIS}

\section{Resultados cuantitativos}

de las diferentes unidades de análisis

En la unidad micro, en primer lugar, se consideraron los 162 motivos analizados en los siete sitios registrados directamente. Se advirtió un claro predominio de las representaciones no figurativas versus las figurativas, siendo las líneas los motivos más representados con un total de 88 ejemplares. En cuanto al tipo de motivo a nivel figurativo/no figurativo por sitio, en el continente la mitad de los yacimientos (23 de 46) presentó ambos tipos de representaciones, mientras que en los canales esto ocurrió en cuatro de los cinco sitios, siendo Cueva de los Niños (LO6) la excepción. Es importante mencionar que ningún sitio presenta únicamente motivos de tipo figurativo. A partir de los antecedentes bibliográficos, no se logró contar con el número total de motivos, por lo que sólo se trabajó con presencia/ausencia de tipos de figuras.

Por otra parte, con respecto a la muestra analizada directamente y a los motivos figurativos (Tabla 2), se aprecia que los antropomorfos son las figuras más representadas $(n=31)$, siendo en su totalidad de tipo esquemático. En cuanto a la técnica de elaboración de este tipo de motivo, considerando los datos aportados por la bibliografía, se observa una diferencia entre zonas, principalmente a nivel de continente. Es así como en cerro Benítez/lago Sofía (LO1) fueron dibujados a partir de la técnica lineal, mientras que en Torres del Paine (LO2) se empleó esta última como la pintura plana. Por otro lado, en Campo Volcánico de Pali Aike (LO3) tendieron a ser elaborados a partir de pintura plana. En los canales se advirtió la utilización de ambas técnicas. 
Tabla 2. Cantidad de tipos de motivos figurativos por área, según sitio y tipo de registro (directo y bibliografía). La no presentación de valores, en algunos apartados, es debido a que no cuentan con información o el tipo de motivo no se encuentra representado en el área.

\begin{tabular}{|c|c|c|c|c|c|c|c|c|c|c|c|c|c|}
\hline & & \multicolumn{12}{|c|}{ Tipos de motivos figurativos } \\
\hline & & \multicolumn{3}{|c|}{ Antropomorfo } & \multicolumn{3}{|c|}{ Zoomorfo } & \multicolumn{3}{|c|}{ Impronta de mano } & \multicolumn{3}{|c|}{ Tridígito } \\
\hline \multirow[t]{2}{*}{ Sector } & Área & $\begin{array}{l}\stackrel{n}{\stackrel{0}{*}} \\
\text { 乙 }\end{array}$ & 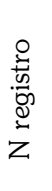 & 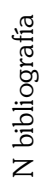 & $\begin{array}{l}\stackrel{0}{0} \\
\text { z } \\
z\end{array}$ & 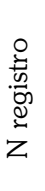 & 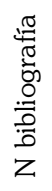 & $\begin{array}{l}\stackrel{0}{:} \\
\text { 乙 } \\
\text { 乙 }\end{array}$ & 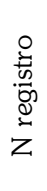 & 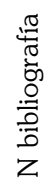 & $\begin{array}{l}\stackrel{0}{0} \\
\text { Z } \\
z\end{array}$ & 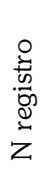 & 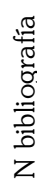 \\
\hline & $\begin{array}{c}\text { LO1 } \\
\text { cerro } \\
\text { Benítez/lago Sofía }\end{array}$ & 1 & 3 & - & 3 & 3 & 1 & 1 & 1 & - & - & - & - \\
\hline \multirow[t]{3}{*}{ Continente } & $\begin{array}{c}\text { LO2 } \\
\text { Torres del Paine } \\
\text { LO3 }\end{array}$ & 2 & 10 & - & 2 & 4 & - & 1 & 4 & - & 1 & - & - \\
\hline & $\begin{array}{c}\text { Campo Volcánico de } \\
\text { Pali Aike/río Gallegos } \\
\text { LO4 }\end{array}$ & 8 & - & 14 & 7 & - & 3 & 6 & - & - & 5 & - & - \\
\hline & $\begin{array}{c}\text { archipiélago } \\
\text { Madre de Dios } \\
\text { LO5 }\end{array}$ & 2 & 15 & - & - & - & - & - & - & - & - & - & - \\
\hline \multirow[t]{3}{*}{ Canales } & $\begin{array}{c}\text { canal Beagle/cabo } \\
\text { de Hornos } \\
\text { LO6 }\end{array}$ & 2 & 3 & - & 1 & - & - & - & - & - & - & - & - \\
\hline & $\begin{array}{l}\text { fiordo de Última } \\
\text { Esperanza }\end{array}$ & - & - & - & - & - & - & - & - & - & - & - & - \\
\hline & Total & 15 & 31 & 14 & 13 & 7 & 4 & 8 & 5 & - & 6 & - & - \\
\hline
\end{tabular}

Continuando con las representaciones figurativas (Tabla 2), se identificaron tridígitos sólo en LO2 y LO3, mientras que tanto los zoomorfos $(n=7)$ como las improntas de mano $(n=5)$ fueron representados en bajo porcentaje. Con respecto a los zoomorfos se observó una diferencia entre áreas, ya que en LO2 fueron mayormente representados utilizando la tinta plana, mientras que en LO1 fueron dibujados a partir de puntos. De acuerdo a la información en la bibliografía, en LO3 se advirtió que la técnica mayormente utilizada consistió, al igual que LO2, en la pintura plana. En los canales se identificaron zoomorfos sólo en una de las áreas (LO5) en el sitio Alero Martín González Calderón (González et al. 2014), pero no se contó con el detalle de la técnica utilizada.

En cuanto a las improntas de mano en negativo y positivo, fueron identificadas en LO1, LO2 y LO3, pese a que su presencia no es comparable con otras zonas de Patagonia, como el río Ibáñez o la cuenca del lago Cardiel (Artigas \& Muñoz, 2015; Artigas et al. 2016; Muñoz \& Artigas, 2016; Guichón, 2018; Cordero et al. 2019; entre otros).
En resumidas cuentas, se puede apreciar cómo a nivel de motivos figurativos se desprende una primera diferencia entre los canales y el continente, ya que en este último fueron representados improntas de mano y tridígitos, motivos totalmente ausentes en los contextos canoeros.

Los motivos no figurativos corresponden al mayor número de figuras, siendo las líneas las más representadas. En una primera aproximación, considerando tanto las representaciones identificadas a partir del registro directo de los sitios como también la información disponible en la bibliografía, se observó una mayor variedad de tipos de motivo en el continente (20 de 22), mientras que en los canales sólo fueron identificados 12 atributos (Fig. 2). A partir de esto se puede inferir una mayor estandarización en los canales en comparación con el continente. Sin embargo, se debe tener presente la baja cantidad de sitios identificados en el primer sector.

Pese a que los puntos y líneas se registraron en ambos sectores, es relevante hacer hincapié, al igual que en los motivos figurativos, en la 


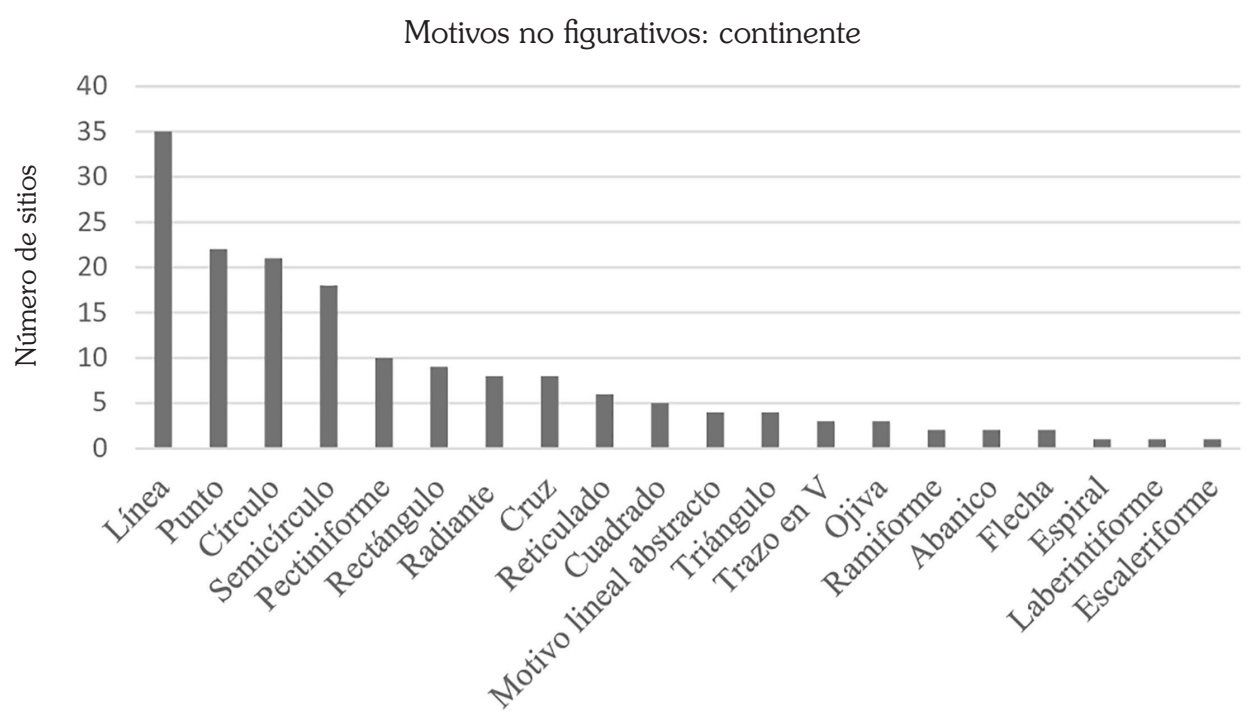

Motivos no figurativos: canales

4

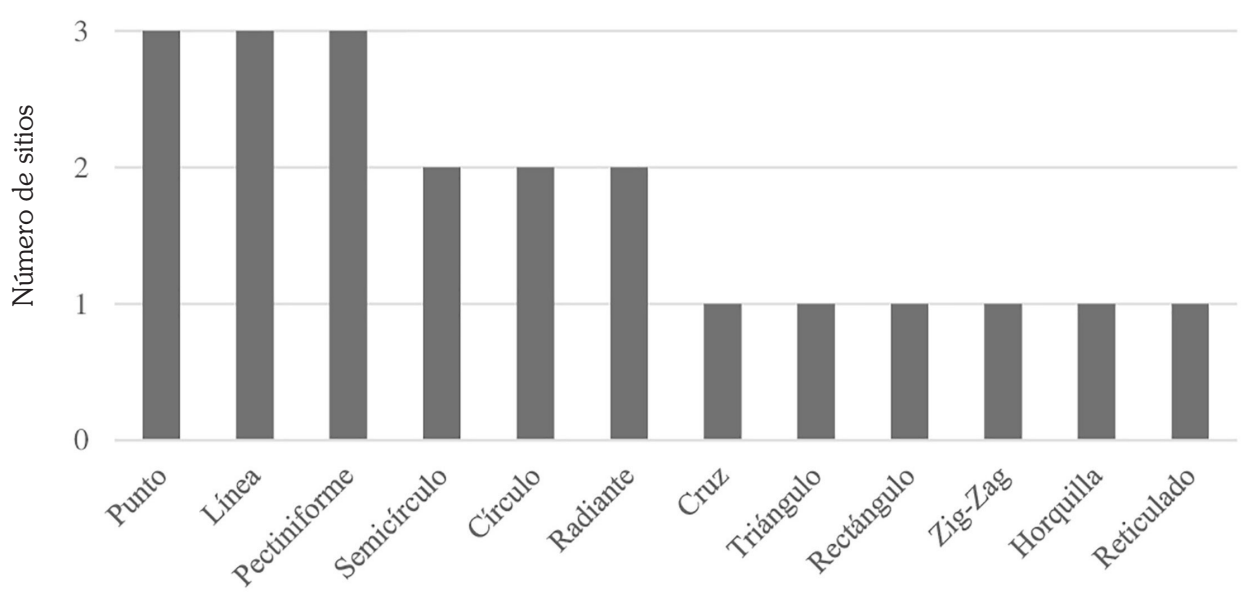

Fig. 2. Comparación entre los distintos tipos de motivos no figurativos presentes tanto en el continente como en los canales.

representación de ciertos motivos en áreas específicas, como los espirales y escaleriformes en LO1, los laberintiformes, cuadrados y trazos en $\mathrm{V}$ en LO3 y las horquillas y zig-zag en la parte norte de los canales (LO4), por lo que se estarían dando también diferencias a nivel de áreas.

En cuanto al color de las representaciones analizadas directamente, tendió a predominar el rojo-anaranjado, mientras que el negro estaría exclusivamente asociado al archipiélago Madre de Dios (LO4). Sin embargo, al incluir los datos bibliográficos, se apreció que la tonalidad roja fue la más utilizada en 41 de los 51 sitios, mientras que el marrón oscuro fue el menos representado, sólo registrándose en el sitio Cerro Benítez 5 (Massone, 1982). En cuanto al negro, también se encuentra presente en Campo Volcánico de Pali Aike, no obstante, los motivos en esta coloración difieren de los de LO4, debido a que fue utilizado en líneas, puntos, antropomorfos, tridígitos y manos 
positivas (Bate, 1970, 1971; Campan et al. 2007; Manzi \& Carballo Marina, 2012), mientras que en los canales se registró en líneas, puntos y antropomorfos. Por lo tanto, las tonalidades también mostrarian diferencias entre áreas más que entre sectores, debido a que, a modo de ejemplo, en LO5 fue utilizado el blanco, que se encuentra ausente en LO4. Por el contrario, en este último se registraron motivos en negro.

En cuanto a la unidad meso, sólo se consideraron los datos provenientes de los siete sitios analizados directamente, debido a que en el resto de los casos no se contaba con el detalle de cada panel. En total se analizaron 29 conjuntos donde un $48 \%$ sólo presentó motivos no figurativos, siendo el área del archipiélago Madre de Dios (LO4) el que presentó la mayor cantidad de paneles. Esto puede traducirse en un mayor aprovechamiento de los espacios disponibles para ser pintados. Por otro lado, los paneles únicamente con representaciones figurativas tienden a emplazarse en los canales, a excepción del conjunto $C$ de Lago Sarmiento-1 (E03). Lo mismo ocurre con los conjuntos únicamente no figurativos. La tendencia cambia con aquellos que presentaron ambos tipos de motivos, situándose en su mayoría en el continente (Tabla 3).

En resumen, en los canales se privilegió la construcción de paneles figurativos en lugares diferentes a aquellos en donde se elaboraron conjuntos no-figurativos, lo que no se observó en el sector continental. Esto podría dar luces respecto a una construcción más reglada y estandarizada de los códigos visuales en los canales, posiblemente asociada con la mayor presencia de grupos cazadores recolectores en el continente durante el Holoceno tardío. Sin embargo, esta información debe ser tratada con cautela, considerando el escaso número de sitios con arte rupestre identificados en los archipiélagos.

Con respecto a la asociación entre motivos, la yuxtaposición prevaleció por sobre el resto, dado que estuvo presente en 14 de los 29 paneles analizados. La superposición nunca se presentó sola en un panel, siempre estuvo acompañada de la yuxtaposición en los paneles, identificándose en cinco conjuntos con un total de 12 motivos (Tabla 3). Gran parte correspondió a motivos figurativos, mientras que la superposición entre figurativos y no figurativos sólo estuvo presente en el archipiélago Madre de Dios. En cuanto a los colores utilizados, el rojo tendió a ser la tonalidad de base, mientras que el color del motivo superpuesto fue variable, yendo desde el blanco (LO2) hasta el negro (LO4).

Si estos datos los comparamos a nivel de sitio con la información bibliográfica, se acrecienta la idea de la superposición como un fenómeno aislado, dado que sólo se encuentra presente en 10 de los 51 yacimientos. En este caso, el lugar donde se estaría dando un mayor énfasis a dicha asociación sería en Campo Volcánico de Pali Aike (LO3), con cinco sitios. Esto podría estar asociado a la ocupación extensiva del Campo Volcánico por grupos cazadores recolectores terrestres durante el Holoceno tardío, debido a la escasez de barreras naturales que pudieran

Tabla 3. Cantidad de paneles por tipo de motivo representado y asociación. En la última columna se muestra el detalle de los conjuntos por sitio de acuerdo a la siguiente nomenclatura: A: Alero Picton 1; B: Cerro Benítez 11; C: Dos Herraduras; D: Grotte du Pacifique; E: Lago Sarmiento-1; F: Lago Sofía; G: Cueva Augusta 1.

\begin{tabular}{|c|c|c|c|}
\hline Variable & Atributo & $\begin{array}{l}\text { Cantidad total } \\
\text { de conjunto }\end{array}$ & Sitio y número de conjunto \\
\hline \multirow{3}{*}{$\begin{array}{l}\text { Tipo de } \\
\text { motivo }\end{array}$} & Figurativo & 5 & D11, E03, D06, A01, G03 \\
\hline & No figurativo & 14 & $\begin{array}{c}\text { A02, B01, C01, C03, D03, D04, D05, D07, D08, D09, } \\
\text { E05, G01, G04, G05 }\end{array}$ \\
\hline & No figurativo/figurativo & 10 & $\mathrm{C} 02, \mathrm{C} 04, \mathrm{D} 01, \mathrm{D} 02, \mathrm{D} 10, \mathrm{E} 01, \mathrm{E} 02, \mathrm{E} 04, \mathrm{~F} 01, \mathrm{G} 02$ \\
\hline \multirow{4}{*}{ Asociación } & Yuxtaposición & 14 & $\begin{array}{c}\text { A02, B01, C01, C02, D01, D04, D07, D08, D10, D11, } \\
\text { E01, E05, F01, G05 }\end{array}$ \\
\hline & Motivo aislado & 7 & $\mathrm{C} 03, \mathrm{D} 05, \mathrm{D} 06, \mathrm{D} 09, \mathrm{E} 03, \mathrm{G} 03, \mathrm{G} 04$ \\
\hline & Superposición y yuxtaposición & 5 & A01, C04, E04, G01, G02 \\
\hline & Yuxtaposición y motivo aislado & 3 & D02, D03, E02 \\
\hline
\end{tabular}


impedir la movilidad (Gómez Otero, 19871988). Sin embargo, en base a la escasez de superposiciones, también se puede inferir un único momento de realización de las pinturas (Charlín \& Borrero, 2012; Manzi \& Carballo Marina, 2012). Finalmente, a nivel general, en el sector continental existe un mayor número de superposiciones de un mismo color (rojo), siendo la excepción Cueva La Leona (Bate, 1970).

En la unidad macro, al nivel de tipo de sitio, existe una supremacía del atributo alero con un $57 \%$. Un $15 \%$ son bardas o paredones, $14 \%$ son cuevas y $8 \%$ rocas aisladas. En un $6 \%$ de la muestra no se contó con información respecto a esta categoría. La elección en cuanto a la utilización de aleros para plasmar arte rupestre pudo estar asociada a la alta disponibilidad de este tipo de reparos en las diferentes áreas, a excepción de LO4 en donde su naturaleza kárstica favorece la formación de cuevas. Cabe destacar que, pese a que existen cuevas en la parte continental en donde se han registrado ocupaciones (ej.: cueva Pali Aike y cueva del Medio), éstas no fueron utilizadas para realizar arte rupestre.

Siguiendo en esta línea, resulta interesante la comparación entre la cantidad de motivos por sitio y su superficie, lo que lleva a concluir que no existe relación entre ambas variables, es decir, no necesariamente una mayor superficie involucra una mayor cantidad de representaciones, como tampoco una mayor cantidad de paneles. Esto se advierte a partir del estudio de 15 sitios correspondientes a los siete registrados y ocho provenientes del corpus bibliográfico. Para dicho propósito se dividieron los yacimientos en tres intervalos diferentes, además de considerar el promedio de representaciones por intervalo (Fig. 3). En los sitios de menor y mediana superficie, el promedio fue de 18 y 53,3 respectivamente, mientras que en los de mayor superficie el promedio fue de 38. Otro ejemplo está dado por la Grotte du Pacifique (LO4), sitio que posee el mayor número de paneles y motivos pero no la mayor superficie, mientras que Lago Sofía (LO1) es el yacimiento más grande pero presenta tan sólo 14 representaciones.

\section{Análisis Factorial de}

Correspondencia y Clasificación Jerárquica

Ascendente en la unidad micro

El Análisis Factorial de Correspondencia (AFC) y la Clasificación Jerárquica Ascendente (CAH) se realizaron, únicamente, a partir de los datos de los siete sitios registrados, con un total de 162 individuos (motivos) y 33 atributos, los cuales se enmarcaron en cuatro variables consistentes en el tipo de motivo, color, técnica y área. Estos fueron analizados en un programa estadístico especializado que entregó la información en distintos planos factoriales, de los cuales se consideraron dos: el

Frecuencia de sitios y motivos por intervalo de supercicie

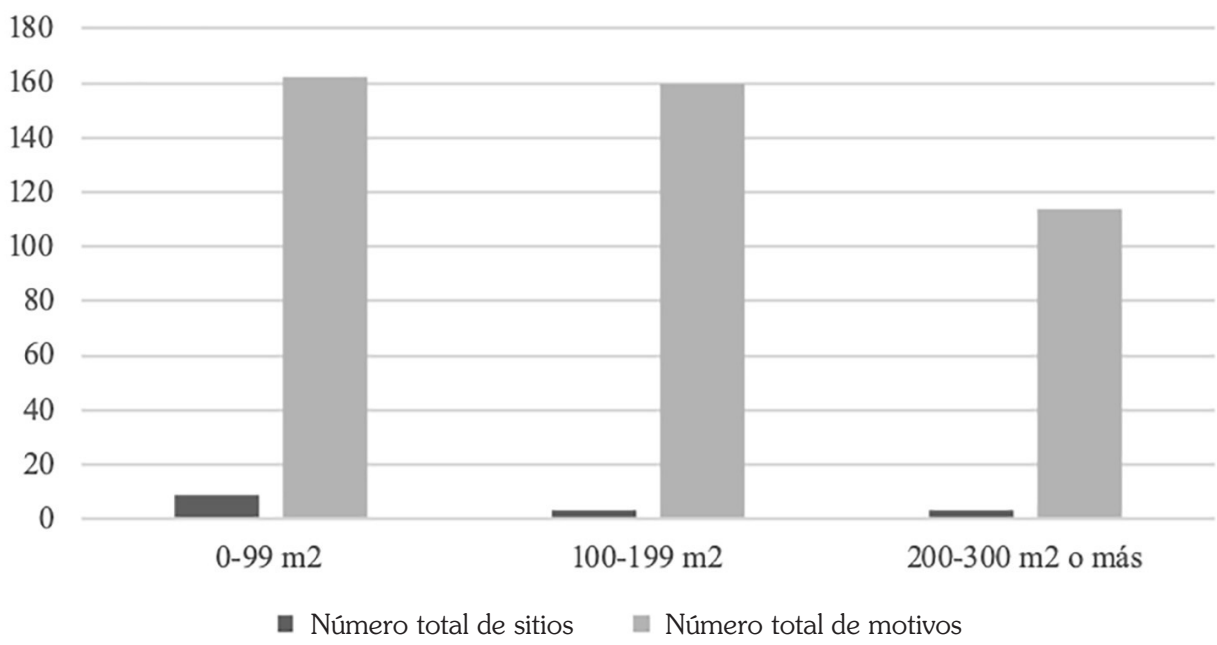

Fig. 3. Relación entre el número de motivos por yacimiento y los intervalos de superficie, considerando la cantidad de sitios involucrados en cada intervalo. 
plano factorial 1 y 2 y 1 y 3 , debido a que tienen un porcentaje acumulativo del $24,2 \%$.

A partir de la información expuesta en los planos 1 y 2 (Fig. 4a) se logró establecer una primera separación entre las improntas de mano, el color blanco, la técnica positiva, cuatro motivos de Lago Sarmiento-1 (E21, E24, E26 y E32) $y$ dos de Dos Herraduras (CO2 y CO6) respecto al resto de atributos $e$ individuos. El resto de los atributos y motivos se reagrupó al costado inferior izquierdo del gráfico, pese a que se pudo observar una ligera diferencia entre la técnica a base de puntos y tinta plana dada por el factor 1 (vertical), y entre el atributo zig-zag y círculo por el eje 2 (horizontal).

En cuanto a los planos factoriales 1 y 3 (Fig. 4b), éstos no presentaron mayores cambios con respecto al anterior, pero se advirtió una separación entre LO1 y LO2 dada por el factor 3. Sin embargo, la aglomeración de atributos en el centro no permitió establecer asociaciones específicas.

Posteriormente, se decidió dejar ciertos atributos como elementos suplementarios, es decir, que fueron excluidos del análisis, pero sin modificarlo. Los atributos ingresados en esta categoría fueron los que sólo presentaban un caso, así como aquellos que se separaron de la muestra general en el primer análisis. Una vez realizado este proceso se procedió a efectuar un nuevo AFC (Fig. 5) que permitió, en

Fig. 4. a) Primer resultado del AFC en los planos factoriales 1 y 2 donde se evidencia las distintas asociaciones marcadas por rectángulos.

Las abreviaturas corresponden a bla: blanco; cir: círculo; man: impronta de mano; pos: positivo; pt: pintura a base de puntos; tpl: pintura tinta plana; zig: zig-zag. b) Análisis Factorial de Correspondencia en los planos 1 y 3 en donde se puede apreciar la separación entre LO1 y LO2 (rectángulos).
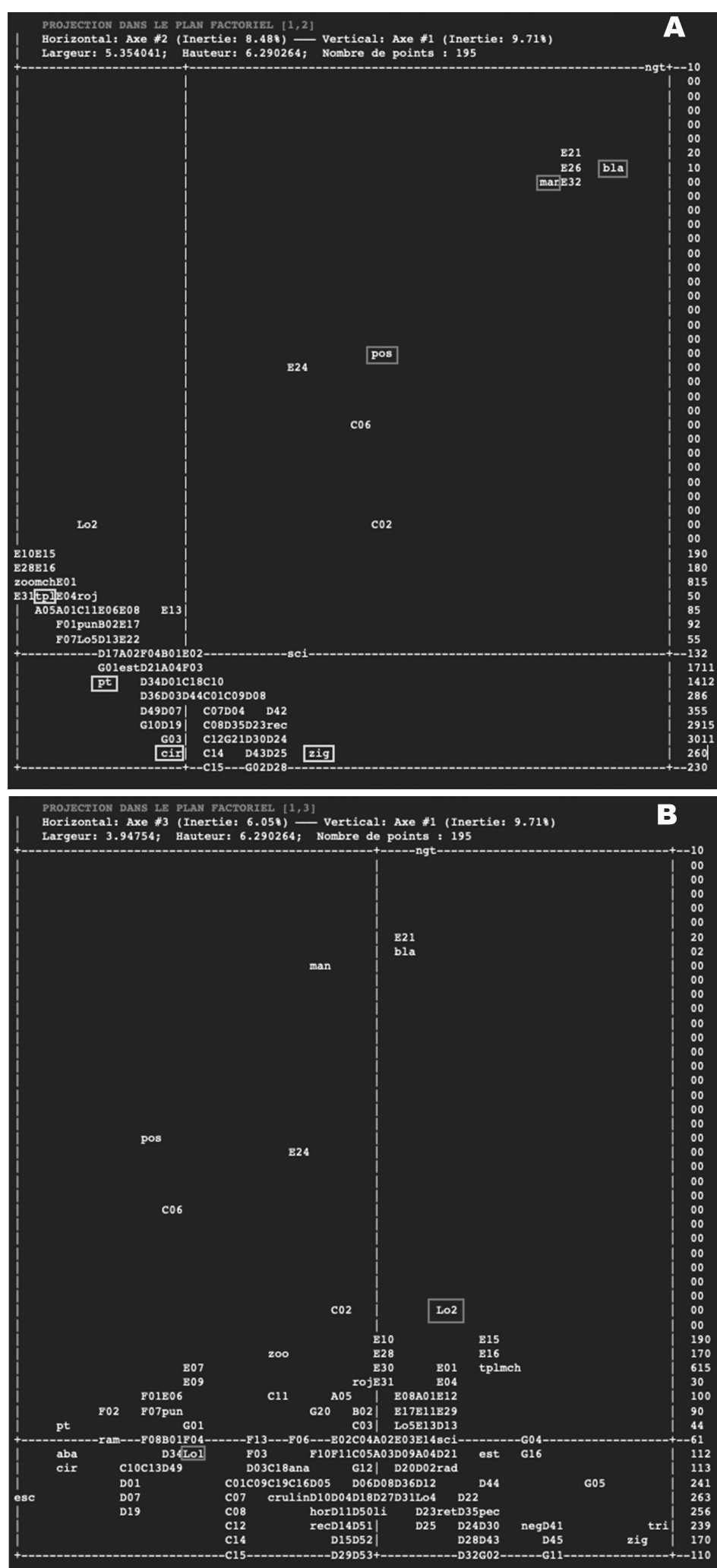

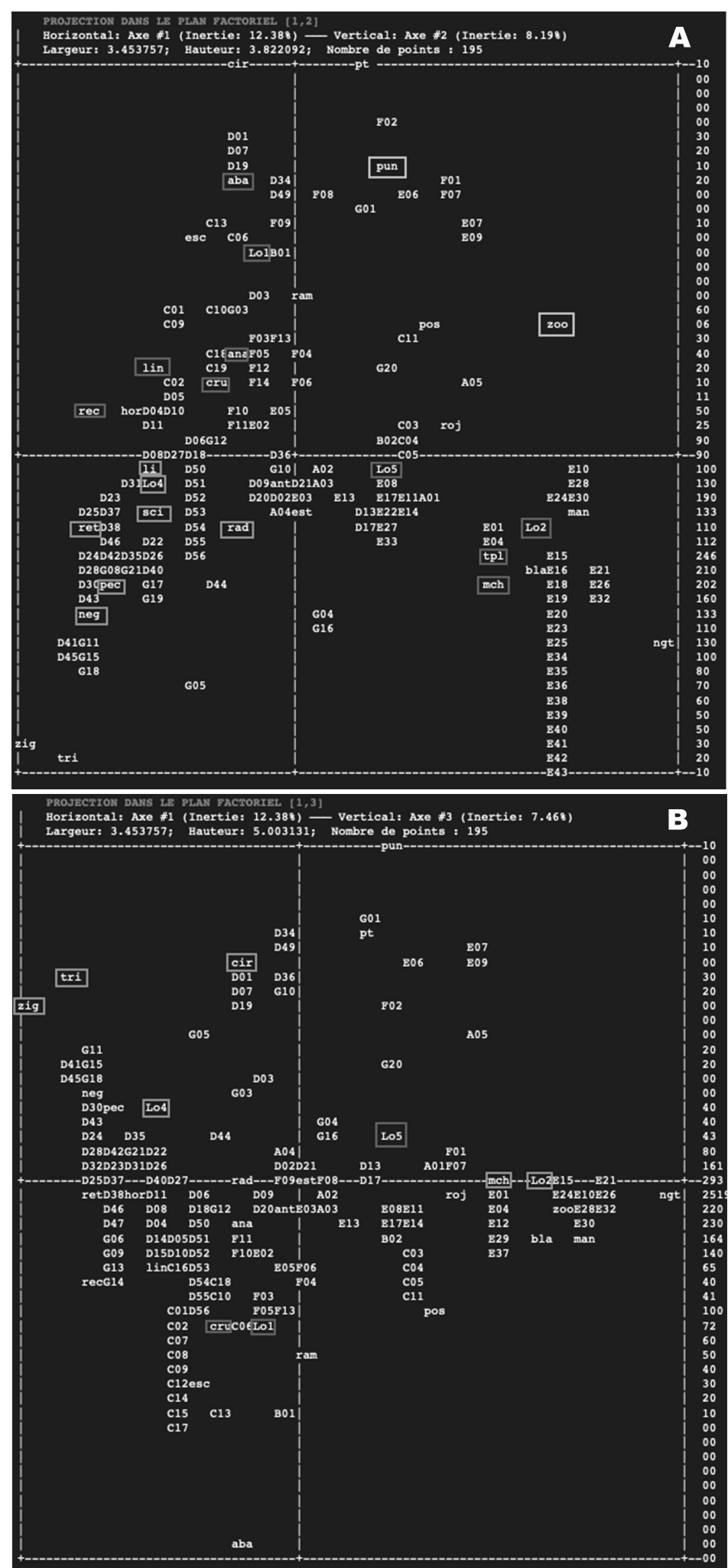

los planos factoriales 1 y 2 , establecer nuevas asociaciones y separaciones. La primera (Fig. 5a) corresponde a la dada por el eje 1, que separó las localidades LO5/LO2, como también LO4 y LO1, mientras que el eje 2 hizo la distinción entre LO1 y LO2. A partir de esto se esbozaron tres agrupaciones distintas; por un lado, las manchas ligadas a LO5, mientras que la técnica de pintura lineal, los semicírculos, radiantes, pectiniformes, reticulados y el color negro se asociaron a LO4. Por otro lado, LO1 se agrupó con los motivos en forma de abanico, las líneas, cruces, rectángulos y el color rojo-anaranjado.

Pese a lo anterior, es relevante mencionar que ciertos atributos como los zoomorfos, los puntos, triángulos y zig-zag no se asociaron a ningún grupo en específico, debido a su posición alejada del eje central del gráfico. Los antropomorfos (ant) parecen ser un caso particular, ya que se encuentran prácticamente sobre el eje 2 y cercanos al centro del gráfico, por lo que se puede inferir que corresponden a un atributo presente en ambos sectores (canales y continente) y en todas las áreas, por lo que la frecuencia de este tipo de motivo es la que podría dar luces respecto a las posibles diferencias entre una localidad $u$ otra.

$\mathrm{Al}$ analizar los planos factoriales 1 y 3 (Fig. 5b) se apreció una clara separación entre LO1 y LO4, estando

Fig. 5. a) AFC en los planos factoriales 1 y 2 dejando elementos en suplementario donde se aprecia la división entre LO5/LO2, LO1 y LO4. Las abreviaturas corresponden a aba: abanico; ana: rojo-anaranjado; cru: cruz; li: pintura lineal; lin: líneas; mch: mancha; neg: negro; pec: pectiniforme; pun: puntos; rad: radiante; rec: rectángulo; ret: reticulado; sci: semicírculo; tpl: pintura tinta plana; zoo: zoomorfo. b) AFC en los planos factoriales $1 \mathrm{y}$ 3 también con elementos en suplementario, a partir del cual se observa con mayor claridad la separación entre LO1 y LO4. Las abreviaturas corresponden a cir: círculo; cru: cruz; mch: mancha; tri: triángulo; zig: zig-zag. 
Tabla 4. Se exponen las asociaciones entre atributos (tipo de motivo figurativo y no figurativo, color y técnica) y áreas dadas por la CAH, específicamente para LO5 y LO2. Aquellos espacios con guión corresponden a las categorías a las cuales no se pudo asociar un área en particular.

\begin{tabular}{|c|c|c|c|c|}
\hline \multirow{3}{*}{ Área } & \multicolumn{4}{|c|}{ Variable } \\
\hline & \multicolumn{2}{|r|}{ Tipo de motivo } & \multirow{2}{*}{ Color } & \multirow{2}{*}{ Técnica } \\
\hline & Figurativo & No figurativo & & \\
\hline LO5 & Antropomorfo & Línea, radiante & Rojo-anaranjado & Pintura plana \\
\hline- & - & Pectiniforme, reticulado, zig-zag & Negro & - \\
\hline- & - & Círculo, punto & - & Pintura a base de puntos \\
\hline LO2 & Zoomorfo & Mancha & Blanco, rojo & Pintura plana y negativo \\
\hline
\end{tabular}

el primero agrupado con las cruces, mientras que el segundo con los círculos, zig-zag y triángulos, elementos que anteriormente no presentaban asociación alguna.

Finalmente, se realizó la Clasificación Jerárquica Ascendente con los resultados del último AFC. Únicamente dos tipos de motivos se asociaron a áreas específicas: LO5 agrupado con los antropomorfos y LO2 con los zoomorfos (Tabla 4).

En conclusión, gracias al AFC se pudieron establecer tres agrupaciones, debido a que existe una separación entre LO2/LO5 y LO1/LO4 dada por el eje 1, y entre LO1 y LO4 por el eje 2. Por lo tanto, LO2/LO5 se caracterizan por la pintura plana y las manchas, mientras que LO1 se asocia a los motivos en forma de abanico, cruz, línea, rectángulo y la coloración rojo-anaranjado. Por último, LO4 está representado por la pintura lineal, los semicírculos, motivos radiantes, pectiniformes y reticulados, como también por el color negro. Estos resultados fueron complementados por la $\mathrm{CAH}$ que permitió generar una distinción entre LO5 y LO2, asociando esta última a las representaciones zoomorfas (Tabla 4).

\section{DISCUSIÓN}

En base a las variables, atributos y análisis estadísticos realizados, se observa que las diferencias en el arte rupestre no sólo se estarían dando a nivel de sectores, sino también a la escala de localidad (áreas). En relación a las principales diferencias entre los canales y el continente, destaca la presencia $\mathrm{y} / \mathrm{o}$ ausencia de ciertas representaciones. Por ejemplo, en el continente fueron realizados dos tipos de motivos ausentes en los canales, consistentes en los tridígitos y las improntas de mano. Los primeros inclusive fueron plasmados a partir de grabados en LO3 (Manzi et al. 2015), técnica totalmente ausente en otras áreas y en el sector de los canales. Si partimos de la base que el arte rupestre es un elemento del contexto arqueológico a través del cual se expresan mensajes y se intercambia información (Wobst, 1977; Wiessner, 1983, 1985; Barton et al. 1994; Domingo Sanz, 2005), se puede interpretar que los códigos asociados a esta clase de motivos no fueron utilizados y/o comprendidos por los grupos de cazadores recolectores marinos. Los tridígitos han sido tradicionalmente definidos como improntas de ñandú, animal inexistente en los contextos de los cazadores recolectores marinos asociados a los archipiélagos de Patagonia sur. Aunque en otras zonas de Patagonia se han identificado representaciones de animales que no existen en el contexto inmediato de las ocupaciones, como por ejemplo en el Ibáñez Medio (Artigas \& Muñoz, 2015; Artigas et al. 2016; Muñoz \& Artigas, 2016; Cordero et al. 2019), dichos lugares no se encuentran separados por barreras geográficas como lo están el estrecho de Magallanes o los archipiélagos. Por esta razón es viable postular que, pese a que esta clase de representación pudo haber sido conocida en los canales, la complejidad de su mensaje y la distancia con el emisor (en este caso el continente) no favorecieron su adopción y apropiación (Wobst, 1977). De la misma forma, la ausencia de improntas de mano pudo estar 
ligada a la apropiación de dicho código por los cazadores recolectores terrestres. Los cazadores recolectores marinos, por lo tanto, pudieron haberle dado prioridad a otro tipo de motivo como los antropomorfos, lo que explicaría la abundancia de esta clase de representación en el sector.

En relación al color, el rojo fue utilizado en todos los contextos, mientras que el negro se asocia principalmente a la parte norte de los canales. Respecto a la asociación de los motivos en los diferentes paneles analizados, la yuxtaposición y la superposición se identificaron tanto en el continente como en los canales. Lo mismo ocurre respecto al tipo de sitio, dado que en ambos sectores las representaciones fueron realizadas en aleros y cuevas.

$\mathrm{Si}$ examinamos la información por localización, considerando las seis áreas definidas en este estudio a partir del registro de los sitios y los antecedentes bibliográficos disponibles, se logra determinar diferencias entre áreas. Gracias a la información presentada en la Tabla 5, se aprecia que las diferencias a nivel continental se dan en cuatro categorias: los motivos figurativos, no figurativos, el color y en la asociación entre representaciones dentro de los conjuntos, específicamente en la superposición.

A partir de los resultados recién expuestos se puede ver que ciertos tipos de motivos están siendo representados indistintamente en todas las áreas, dado que lo que cambia es la técnica y el color con los cuales fueron manufacturados, por lo que parece ser que son las formas de construir las representaciones las que le dan el significado al motivo. Por lo tanto, son los aspectos técnicos, colores y asociaciones los que pueden indicar posibles diferencias entre grupos que habitan un mismo espacio, lo que podría estar asociado a una mantención y promoción de la identidad (Wobst, 1977). Es posible inferir que es la variación formal de las representaciones la que transmite información en base a una identificación personal y social (Wiessner, 1983, 1985). Esta variación en los códigos y mensajes estaría además asociada directamente al período al cual han sido asignadas de forma relativa las pinturas, es decir, el Holoceno tardío (Bate, 1970, 1971; Massone, 1982), específicamente los últimos 3.000 años. Este período se caracteriza por una ocupación efectiva del espacio disponible en la región por diferentes grupos (Borrero, 1989-1990), lo que pudo haber conllevado a una competencia por ciertos recursos y nichos ecológicos, fenómeno que favoreció la diferenciación social y la delimitación territorial, y que pudo haber sido plasmado en el arte rupestre (Barton et al. 1994). Cabe destacar que este tipo de proceso ha sido identificado también en otras partes de Patagonia como el río Pinturas, río Belgrano, lago Posadas-Pueyrredón Norte y la zona del lago General Carrera/Buenos Aires, donde ha sido registrada una fragmentación estilística hacia el 3.800-3.000 años AP (Aschero, 2012).

Por otro lado, para el sector de los canales las diferencias entre áreas se evidencian en los motivos no figurativos, el color, la superposición y la disposición de las representaciones en los diferentes paneles (Tabla 5). Estos aspectos permiten separar el archipiélago Madre de Dios (LO4) del canal Beagle/cabo de Hornos (LO5) y del fiordo de Última Esperanza (LO6), debido a que estas dos últimas áreas tienden a asemejarse entre sí. En general, LO4 se caracteriza por los zig-zag y los motivos en forma de horquilla, como también por el color negro, el cual está ausente en el resto de los contextos de este sector. La superposición en LO4 se registró sólo entre motivos no figurativos y siempre en negro sobre rojo. Por el contrario, en LO5 la única superposición identificada fue entre motivos figurativos (antropomorfos) en rojo. En consecuencia, estas diferencias también pueden ser explicadas en base a la presencia de diferentes grupos en los canales que pudiesen haber utilizado el arte rupestre para diferenciarse. Esto, además, tendría sus bases en la naturaleza de los soportes empleados para la elaboración de las pinturas, dado que en LO4 se utilizaron sólo cuevas profundas, mientras que en LO5 y LO6 aleros, por lo que la transmisión de información pudo haber estado más restringida en el primer caso.

Sin embargo, no podemos dejar de lado la posibilidad que ciertos códigos visuales y mensajes pudieron haber sido transmitidos entre continente y canales (y viceversa), lo que se ve fundamentado en los resultados aportados por el AFC que muestran una asociación entre LO5 y LO2. Cabe destacar que la interacción costa-continente ha sido registrada en ciertas áreas de Patagonia como lo son Campo Volcánico de Pali Aike y Tierra del 


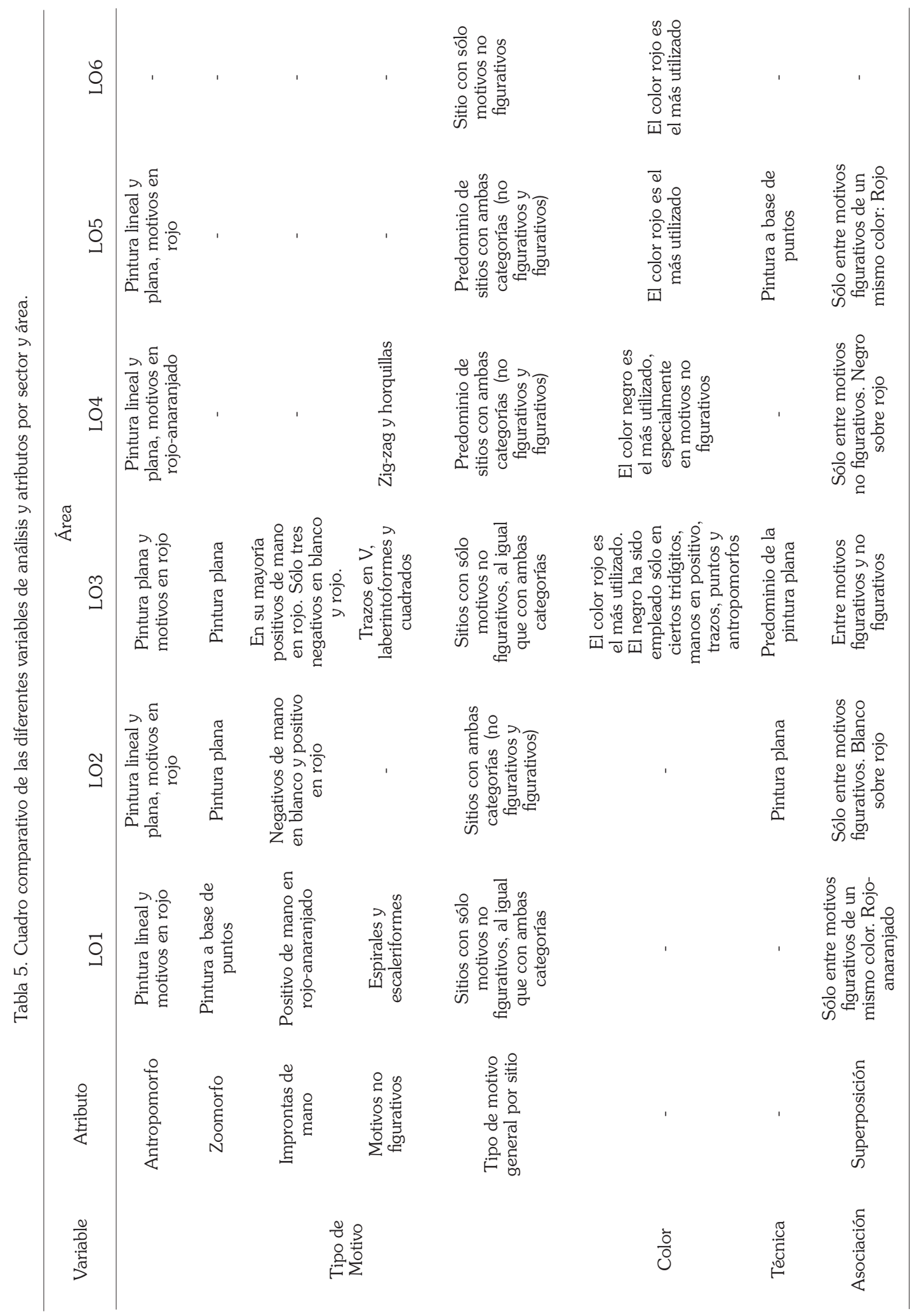


Fuego, gracias al análisis de isótopos estables y de la identificación de recursos marinos en los contextos arqueológicos. Esta información ha permitido establecer el consumo de recursos marinos que fueron ingresados en contextos terrestres durante el Holoceno tardío (Barberena, 2002, 2008; Charlín \& Borrero, 2012; Miotti, 2012). Además, existen antecedentes etnográficos que avalan el desplazamiento de grupos a grandes distancias, como fue el caso de un cazador recolector marino Kawésqar (canales) entre las bandas de Aónikenk (cazadores recolectores terrestres) asentadas en la costa central del estrecho de Magallanes, lo que llevó a postular un régimen de visitas entre ambos grupos (Borrero et al. 2011).

Finalmente, si comparamos la información recién expuesta con las modalidades estilísticas planteadas para la parte continental de Patagonia sur (Bate, 1970, 1971; Massone, 1982), y que han sido retomadas por diversos autores (Gallardo, 2009; Charlín \& Borrero, 2012; Manzi \& Carballo Marina, 2012; Charlín, 2014, etc.), se pueden establecer diferencias entre las distintas áreas que pueden estar ligadas a la ocupación de dichos territorios por diferentes grupos. No obstante, los resultados de los análisis muestran que las diferencias están principalmente ligadas a la técnica y al color de los motivos figurativos, como también a ciertos tipos no figurativos y a la asociación entre motivos dada por la superposición. Por lo tanto, se considera poco aplicable la definición tradicional de estilos sobre la base de elementos tales como las líneas y los puntos, debido a que son una constante en el arte rupestre de esta región. Se puede aplicar el mismo criterio para la esquematización de los motivos zoomorfos y antropomorfos (Bate, 1970, 1971), ya que no existen figuras de tipo naturalistas.

En cuanto a la modalidad Lago Sofía que tradicionalmente fue ligada a la técnica a base de puntos, este aspecto debe sólo considerarse para los motivos zoomorfos, debido a que los resultados de la CAH mostraron que dicho tipo de técnica se encuentra más asociada a LO5.

Por último, en relación al Estilo Río Chico que ha sido ampliamente estudiado en la región, desgraciadamente no se contó con el detalle de las representaciones y paneles por sitio, por lo que su estudio pudo realizarse únicamente desde una aproximación bibliográfica. No obstante, a lo que ya ha sido definido por otros autores se debe agregar los trazos en $\mathrm{V}$, laberintiformes y cuadrados. Esto permite dejar de lado otros elementos tradicionales de esta modalidad, como las paralelas atravesadas por un trazo perpendicular (Bate, 1970, 1971) identificadas en el presente estudio como pectiniformes, y las hojas de palmero o ramiformes, dado que esta clase de elementos también fue detectada en LO1, específicamente en el sitio Lago Sofía.

\section{CONCLUSIÓN Y PROYECCIONES}

En resumen, el análisis de 51 sitios dispersos en seis áreas geográficas, específicamente tres en el continente (LO1, LO2 y LO3) y tres en los canales (LO4, LO5 y LO6), ha permitido obtener diferentes tipos de información según su fuente, sea ésta bibliográfica o registro directo. Gracias a esto se puede establecer que, inicialmente, existirian diferencias generales entre el arte rupestre del continente y de los canales, las cuales pueden apreciarse sobre todo en las unidades de análisis micro y meso, es decir, a nivel de motivo y de sus asociaciones dentro de los conjuntos.

Al comparar la información con los diferentes estilos propuestos para Patagonia meridional, se puede apreciar cómo en el Estilo Río Chico pueden ser ingresados nuevos elementos, como es el caso de los trazos en $\mathrm{V}$, laberintiformes y cuadrados, además de la superposición entre elementos figurativos sobre no figurativos y viceversa. Las improntas de mano en positivo, espirales $y$ escaleriformes, se asocian a la modalidad Lago Sofía y el predominio de zoomorfos, improntas de mano en negativo blancas y la superposición de elementos figurativos blancos sobre rojo al Estilo Lago Sarmiento.

Para el sector de los canales, pese a que no existen estilos definidos, se puede proponer lo que tradicionalmente se ha denominado como grupos estilísticos, entendidos como conjuntos con similitudes temáticas, de ejecución y de asociación entre motivos figurativos y no figurativos (Gradín et al. 1976; Aschero, 2012). Se propone en primera instancia uno asociado a Madre de Dios y un segundo denominado del Extremo Sur. 
El grupo estilístico Madre de Dios (Fig. 6) se encuentra representado por los sitios emplazados en el archipiélago del mismo nombre y se caracteriza por motivos figurativos, exclusivamente antropomorfos en rojo-anaranjado realizados principalmente a partir de pintura lineal y plana. En cuanto a los motivos no figurativos exclusivos de esta modalidad se encuentran los zig-zag y las figuras en forma de horquilla, mientras que el color predominante tiende a ser el negro. La superposición se registra entre motivos no figurativos negro sobre rojo.

El grupo estilístico del Extremo Sur (Fig. 7) comprende los sitios emplazados en el canal Beagle/cabo de Hornos como aquellos del fiordo de Última Esperanza. Se caracteriza por presentar

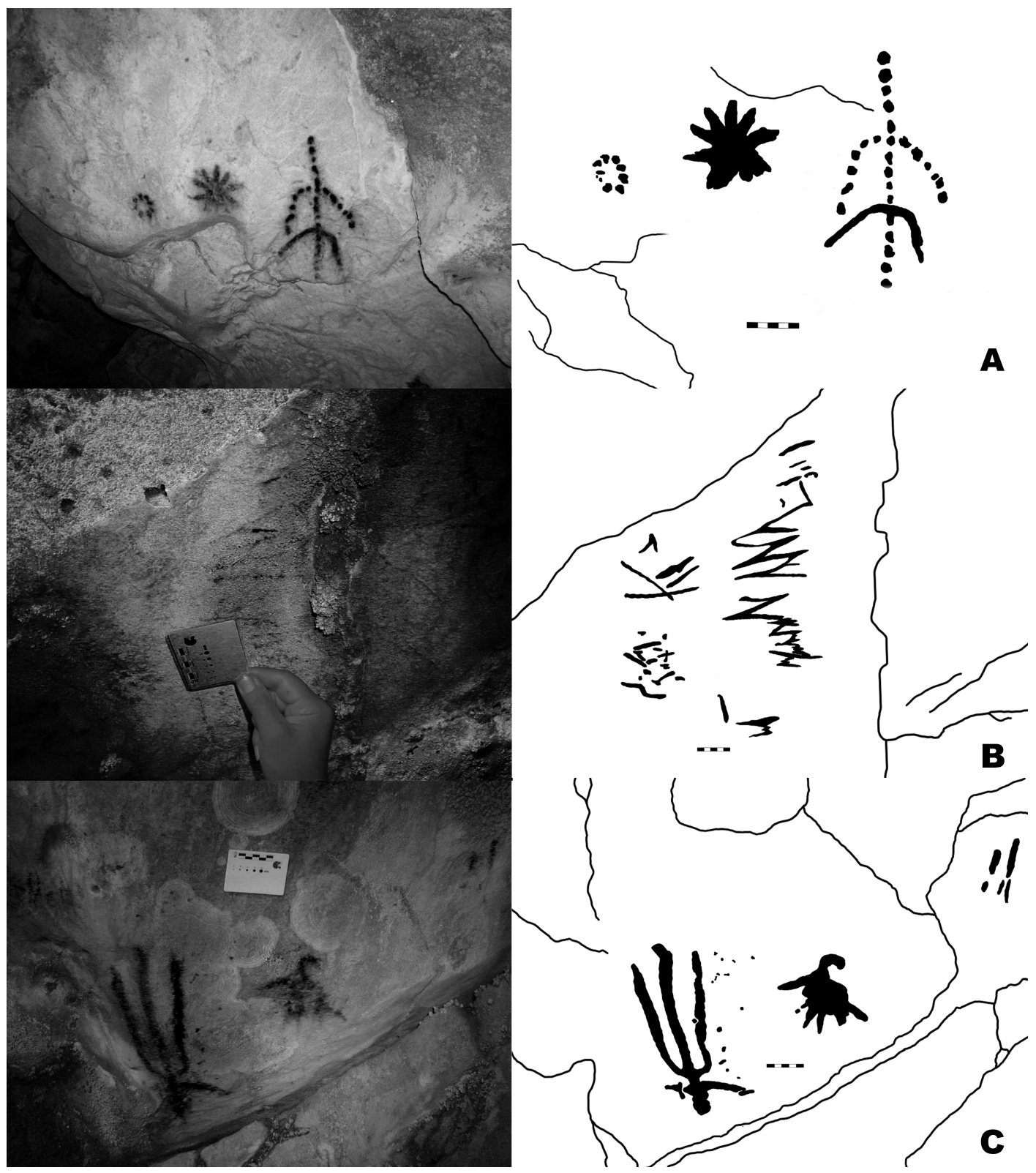

Fig. 6. Representaciones figurativas y no figurativas que caracterizan el grupo estilístico Madre de Dios: a) antropomorfo rojo-anaranjado; b) zig-zag en negro; c) figura en forma de horquilla en rojo (fotografías de N. Aguilera) 


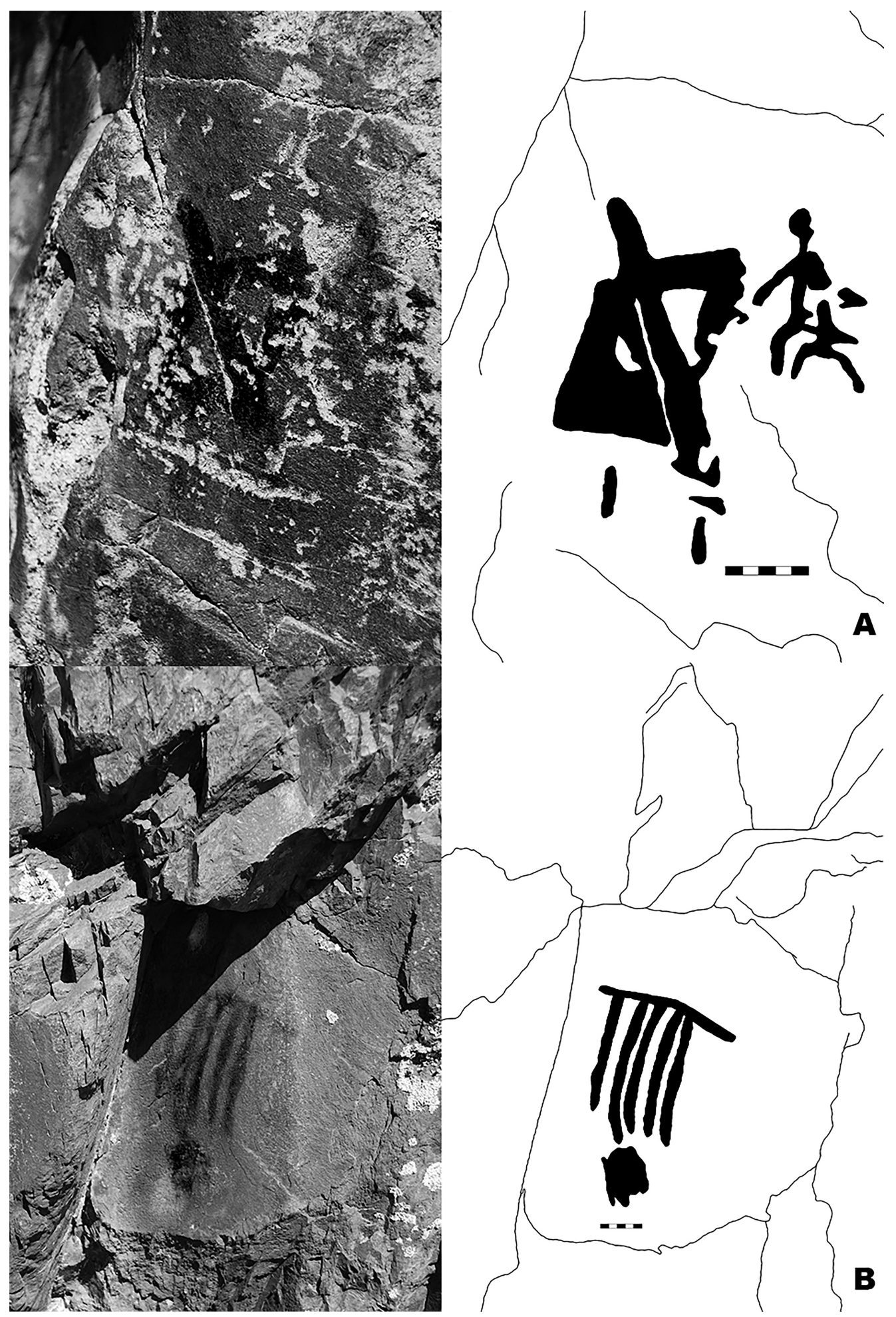

Fig. 7. Representaciones figurativas y no figurativas que caracterizan el grupo estilístico del Extremo Sur: a) antropomorfos en rojo; b) motivo lineal en color rojo-anaranjado. 
una mayor frecuencia de antropomorfos en color rojo y blanco, como también de zoomorfos. Está asociado a líneas y a las tonalidades rojo y rojoanaranjado. En cuanto a la superposición sólo se da entre motivos figurativos rojos.

Como se postuló con anterioridad, es posible que las diferencias observadas entre distintas localidades estén ligadas a un rol comunicativo del arte rupestre como contenedor de mensajes y códigos (Wobst, 1977; Wiessner, 1983, 1985), producto de las condiciones sociales y ambientales que prevalecieron durante el Holoceno tardío en la región. La tendencia a una ocupación efectiva del espacio pudo generar situaciones específicas, tales como la concurrencia de diversos grupos en nichos ecológicos específicos o la simple necesidad de diferenciarse del otro (Wiessner, 1985). Estas distinciones formales han permitido la identificación de diferentes grupos que han utilizado motivos específicos, como las improntas de mano, los zoomorfos y antropomorfos. No obstante, estas diferencias no deben ser vistas como fronteras rígidas, dado que estos grupos continúan con la elaboración de elementos comunes como los puntos y las líneas.

Por lo tanto, esta hipótesis debe ser examinada a la luz de nuevos registros, no sólo en relación al arte rupestre mismo, sino además al contexto estratigráfico que los acompaña, porque, aunque las escasas excavaciones realizadas han permitido establecer una cronología ligada al Holoceno tardío (Bate, 1970, 1971; Massone, 1982; Gómez Otero, 1987-1988; Campan et al. 2007), no se puede descartar la posibilidad de que las diferencias sean producto de diferentes cronologías.

En conclusión, se han podido establecer similitudes y diferencias entre los canales y el continente a través del análisis del arte rupestre, además de complementar los estilos anteriormente planteados para esta zona de Patagonia, junto con la definición de dos nuevas modalidades estilísticas para los canales. Esto da cuenta del posible intercambio de información a partir de códigos visuales entre distintos grupos que pudieron haber interactuado entre sí. No obstante, estos resultados corresponden a una primera sistematización en base a la comparación de ambos sectores, por lo que se hace necesario continuar con esta labor.

\section{AGRADECIMIENTOS}

Mi inmensa gratitud a Marianne Christensen, quien dirigió la memoria de máster que da origen a este artículo; además de Georges Sauvet, ya que sin su ayuda hubiese sido imposible realizar los análisis estadísticos. Eterna gratitud a Fabiana Martin por su apoyo al momento de registrar los sitios y a Nelson Aguilera por proporcionarme las fotografías (de su autoría) de Grotte du Pacifique y Cueva Augusta 1 en Madre de Dios. Finalmente, agradezco a la Agencia Nacional de Investigación y Desarrollo (ANID)/Subdirección de Capital Humano/Programa de Becas/DOCTORADO BECAS CHILE/2020-72210018 y al proyecto Fondecyt 1190984 a cargo de Flavia Morello, debido a que permitirán seguir desarrollando esta línea de trabajo.

\section{BIBLIOGRAFÍA}

Acevedo, A., \& Fiore, D. (2020). Imágenes, códigos y comunicación: Un análisis del arte rupestre en el extremo sur del macizo del Deseado (Patagonia, Argentina). Arqueología, 26(2), 127-155.

Acevedo, A., Fiore, D., \& Franco, N. (2013). Imágenes en las rocas: Uso del espacio y construcción del paisaje mediante el emplazamiento de arte rupestre en dos regiones de Patagonia centro-meridional (Argentina). Espacio, tiempo y forma, 6, 17-53.

Acevedo, A., Fiore, D., Franco, N., \& Ocampo, M. (2014). Arte y espacio. Estructuración de los repertorios de arte rupestre en los cañadones Yaten Guajen y El Lechuza (margen norte del río Santa Cruz, Patagonia, Argentina). Mundo de Antes, 8(3), 9-33.

Artigas, D., \& Muñoz, C. (2015). Arte rupestre en el curso medio del río Ibáñez: retomando el camino de la integración de las manifestaciones artísticas al contexto regional. En Actas XIX Congreso de Arqueología Chilena (pp. 507-514). Arica: Sociedad Chilena de Arqueología.

Artigas, D., Muñoz, C., \& Lucero, V. (2016). Dame una manito: integrando el contexto del arte rupestre a la arqueología del Ibáñez Medio. En F. Oliva, A. M. Rocchietti \& F. S. Banfi. Arte rupestre: lugares y regiones (pp. 559568). Rosario: Centro de Estudios Arqueológicos Regionales.

Aschero, C. (2012). Las escenas de caza en Cueva de las Manos: Una perspectiva regional (Santa Cruz, Argentina). En J. Clottes, L'art Pléistocène dans le Monde (pp. 1-19). 
Tarascon-sur-Ariège.

Barberena, R. (2002). Los límites del mar: Isótopos estables en Patagonia Meridional. Buenos Aires, Argentina: Sociedad Argentina de Antropología.

Barberena, R. (2008). Arqueología y biogeografía humana en Patagonia Meridional. Buenos Aires, Argentina: Sociedad Argentina de Antropología.

Barton, C. M., Clark, G. A., \& Cohen, A. (1994). Art as information: Explaining Upper Palaeolithic art in western Europe. World Archaeology, 26(2), 185-207.

Bate, F. (1970). Primeras investigaciones sobre el arte rupestre de la Patagonia. Anales del Instituto de la Patagonia, 1, 15-25.

Bate, F. (1971). Primeras investigaciones sobre el arte rupestre de la Patagonia (segundo informe). Anales del Instituto de la Patagonia, 2, 33-41.

Bird, J. (1988). Travels and archaeology in south Chile. Iowa: University of Iowa Press.

Borrero, L. (1989-1990). Evolución cultural divergente en la Patagonia austral. Anales del Instituto de la Patagonia, 19, 133-140.

Borrero, L. A., Martin, F. M., \& Barberena, R. (2011). Visits, "Fuegians" and information networks. En Information and its role in hunter-gatherer bands (pp. 249-296). Santa Fe, EE.UU: R. Whallon, W. A. Lovis y R. K. Hitchcock.

Campan, P., Carballo Marina, F., \& Manzi, L. (2007). Arqueología de estancia La Carlota (campo volcánico Pali Aike, Argentina). En Levantando Piedras, Desenterrando Huesos y Develando Arcanos (pp. 687-699). Punta Arenas: F. Morello, M. Martinic, A. Prieto \& G. Bahamonde.

Charlín, J. (2014). Nuevos sitios con representaciones rupestres en la localidad Potrok Aike (Santa Cruz, Argentina). Magallania, 42(1), 183-196.

Charlín, J., \& Borrero, L. (2012). Rock art, inherited landscapes and human populations in southern Patagonia. In A Companion to Rock Art (pp. 381-398). Oxford: J. McDonald \& P. Veth.

Cibois, P. (2006). Principe de l'analyse factorielle. Recuperado de http://cibois.pagesperso-orange.fr/ PrincipeAnalyseFactorielle.pdf

Cibois, P. (2007). Les méthodes d'analyse d'enquêtes. Paris: Les Presses Universitaires de France.

Cordero, R., Muñoz, C., \& Artigas, D. (2019). Reinterpretando paredes: Interacción e intercambio de información en el Ibáñez Medio, Patagonia Central, Chile. Boletín del Museo Chileno de Arte Precolombino, 24(1), 35-53.

Domingo Sanz, I. (2005). Técnica y ejecución de la figura en el arte rupestre levantino. Hacia una definición actualizada del concepto de estilo: Validez y limitaciones (Tesis Doctoral). Universitat de Valencia, Valencia.

Fage, L. H. (2006). Le mystère des indiens Alakaluf. Última Patagonia, pp. 14-21.

Fiore, D. (2016). Las dimensiones espaciales del arte parietal. Estado actual de las investigaciones desde el Cono Sur y propuesta de síntesis metodológica. En Imágenes rupestres. Lugares y regiones (pp. 51-62). Buenos Aires, Argentina: F. Oliva, A. Rocchietti \& F.S. Banfi.

Gallardo, F. (2009). Sobre la composición y la disposición en el arte rupestre de Chile: Consideraciones metodológicas e interpretativas. Magallania, 37(1), 85-98.

Gómez Otero, J. (1987-1988). Investigaciones arqueológicas en el alero Potrok-Aike (provincia de Santa Cruz): Una revisión de los períodos IV y V de Bird. Relaciones de la Sociedad Argentina de Antropología, 17(1), 173200.

González, M., Gañán, M., \& Serrano, A. (2014). Primer registro de arte rupestre en Tierra del Fuego. Magallania, 42(3), 175-181.

Gradin, C., Aschero, C., \& Aguerre, A. M. (1976). Investigaciones arqueológicas en la Cueva de las Manos estancia Alto Río Pinturas (provincia de Santa Cruz). Relaciones de la Sociedad Argentina de Antropología, 10, 201-250.

Guichón, F. (2018). Redes de información durante el Holoceno medio y tardio en Patagonia meridional. Estudio de las representaciones rupestres en la cuenca del lago Cardiel y sur de la meseta del Strobel [Tesis de Doctorado inédita]. Facultad de Filosofía y Letras, Universidad de Buenos Aires.

Harman, J. (2008). Using decorrelation Stretch to enhance rock art images. Recuperado 13 de marzo de 2019, de http://www.dstretch.com/AlgorithmDescription.html

Jaillet, S., Fage, L.-H., Maire, R., \& Tourte, B. (2009). Découverte d'une grotte ornée dans l'archipel de Patagonie chilienne: La Grotte du Pacifique. Spelunca Mémoires, 34, 173-183.

Jaillet, S., Fage, L.-H., Maire, R., \& Tourte, B. (2010). La Grotte du Pacifique (Chili): Première grotte ornée de l'archipel de Patagonie. International Newsletter on Rock Art, 58, 1-8.

Lamassé, S., Dallo, A., Alerini, J., Deruelle, B., Dumont, L., \& Bonnot, G. (2019). AnalyseSHS: documentation. Recuperado 13 de marzo de 2019, de AnalyseSHS website: http://analyse.univ-paris1.fr/documentation. html\#CAH 
Legoupil, D. (2013). Los cazadores de mamíferos marinos tempranos de la isla Englefield (Patagonia austral). Punta Arenas: Universidad de Magallanes.

Legoupil, D., \& Prieto, A. (1991). Sepultura de niños canoeros en un abrigo pintado de Última Esperanza, Chile. Anales del Instituto de la Patagonia, 20, 133-138.

Leroi-Gourhan, A. (1980). L'empreinte de l'homme. Milán, Italia: Jaca Book.

Maire, R., Tourte, B., Jaillet, S., Despain, J., Laus, B., Brehier, F., Fage, L. H., Morel, L., Pouilly, M., Darty, T., Massault, M., Genty, D., Moreau, C., Wainer, K., Ridoux, V., Dabin, W., Pernette, J. F., Agüero, M., \& Manneschi, M. J. (2009). Geomorphic and archaeological features of coastal caves in Madre de Dios archipelago (Patagonia, Chile). 15th International Congress of Speleology Proceedings, pp. 516-521.

Manzi, L., \& Carballo Marina, F. (2012). Manifestaciones rupestres en el campo volcánico de Pali Aike (Cuenca del río Gallegos, Santa Cruz, Argentina). Magallania, 40(1), 287-306.

Manzi, L., Carballo Marina, F., \& Campan, P. (2015). Grabados rupestres en el sector septentrional del Campo Volcánico de Pali Aike, provincia de Santa Cruz, Argentina: Variabilidad en el "estilo Río Chico". Magallania, 43(2), 189-196.

Martin, F. (2013). Tafonomía de la Transición PleistocenoHoloceno en Fuego-Patagonia. Interacción entre humanos y carnivoros y su importancia como agentes en la formación del registro fósil (1era ed.). Punta Arenas: Ediciones de la Universidad de Magallanes.

Martin, F. M., Todisco, D., Rodet, J., San Román, M., Morello, F., Prevosti, F., Stern, C., \& Borrero, L. A. (2015). Nuevas excavaciones en Cueva del Medio: Procesos de formación de la cueva y avances en los estudios de interacción entre cazadores-recolectores y fauna extinta (Pleistoceno Final, Patagonia Meridional). Magallania (Punta Arenas), 43(1), 165-189.

Massone, M. (1982). Nuevas investigaciones sobre el arte rupestre de Patagonia Meridional chilena. Anales del Instituto de la Patagonia, 13, 73-94.

Massone, M. (1987). Los cazadores paleoindios de Tres Arroyos (Tierra del Fuego). Anales del Instituto de la Patagonia, 17, 47-60.

Massone, M., \& Prieto, A. (2004). Evaluación de la modalidad cultural Fell 1 en Magallanes. Chungara Revista de Antropología Chilena, Volumen Especial, 303-315.

McDonald, J., \& Veth, P. (2011). Information exchange among hunter-gatherers of the western desert of Australia. En Information and its role in hunter-gatherer bands (pp. 221-233). Santa Fe, EE.UU: R. Whallon, W. A. Lovis y R. K. Hitchcock.

Menghin, O. (1952). Las pinturas rupestres de la Patagonia. Runa, 5(1-2), 5-22.

Menghin, O. (1957). Estilos del arte rupestre de Patagonia. Ars Praehistórica, 1, 57-87.

Miotti, L. (2012). El uso de los recursos faunísticos entre los cazadores-recolectores de Patagonia: Tendencias espacio/temporales de las estrategias durante el Holoceno. Archaeofauna, 21, 139-162.

Molina, M. (1972). Nuevos aportes para el estudio del arte rupestre patagónico. Anales de la Universidad de la Patagonia San Juan Bosco, 1(2), 64-167.

Morello, F., Torres, J., Martínez, I., Rodríguez, K., French, C., \& Sierpe, V. (2012). Arqueología de la Punta Santa Ana: Reconstrucción de secuencias de ocupación de cazadores-recolectores marinos del Estrecho de Magallanes, Patagonia Austral, Chile. Magallania, 40(2), 129-149.

Muñoz, C. (2019). L'art rupestre en Patagonie australe et Terre de Feu, Chili: Caractérisation et comparaison des sites du continent et des canaux de l'Extrême Sud. Université Paris 1 Panthéon-Sorbonne.

Muñoz, C., \& Artigas, D. (2016). Dar la mano y tomarse el todo: los sitios rupestres del Ibáñez medio como ventanas de un mundo abierto a los sistemas culturales amplios. En Arqueología de la Patagonia: de Mar a Mar (Ediciones CIEP, pp. 58-66). Coyhaique, Chile: F. Mena.

Muñoz, C., Cordero, R., \& Artigas, D. (2016). El sitio Alero Picton 1: nuevo registro de arte rupestre para los canales fueguinos. Magallania, 44(2), 225-231.

Nami, H., \& Menegaz, A. (1991). Cueva del Medio, aportes para el conocimiento de la diversidad faunística hacia el Pleistoceno Holoceno en Patagonia Austral. Anales del Instituto de la Patagonia, 20, 125-133.

Nami, H., \& Nakamura, T. (1995). Cronología radiocarbónica con AMS sobre muestras de hueso procedentes del sitio Cueva del Medio (Última Esperanza, Chile). Anales del Instituto de la Patagonia, 23, 125-133.

Orquera, L., \& Piana, L. (1986-1987). Composición tipológica y datos tecnomorfológicos y tecnofuncionales de los distintos conjuntos arqueológicos del sitio Túnel 1 (Tierra del Fuego). Relaciones de la Sociedad Argentina de Antropología, 17(1), 201-239.

Ortiz-Troncoso, O. (1975). Los yacimientos de Punta Santa Ana y Bahía Buena (Patagonia Austral). Excavaciones y fechados radiocarbónicos. Anales del Instituto de la Patagonia, 6(1), 93-122.

Pisano, V. (1977). Fitogeografía de Fuego-Patagonia Chile. I: 
comunidades vegetales entre las latitudes $52^{\circ}$ y $56^{\circ} \mathrm{S}$. Anales del Instituto de la Patagonia, 8, 121-250.

Prieto, A. (1991). Cazadores tempranos y tardíos de la cueva 1 del lago Sofía. Anales del Instituto de la Patagonia, 20, 75-97.

Re, A., Belardi, J. B., \& Goñi, R. (2009). Dinámica poblacional tardía en Patagonia Meridional: Su discusión y evaluación a través de la distribución de motivos rupestres. En Crónicas sobre la piedra. Arte rupestre de las Américas (pp. 293-309). Arica, Chile: M. Sepúlveda, L. Briones \& J. Chacama.

San Román, M. (2005). Nuevos hallazgos de sitios de cazadores recolectores marinos tempranos en Isla Englefield, Mar de Otway. Magallania, 33(2), 173-176.
San Román, M. (2016). Informe ejecutivo finalización labores de rescate arqueológico sitio BM 45, sector puente Castor. Ruta Y-905, Km. 23,512. Punta Arenas.

Sepúlveda, M. (2011). Pinturas rupestres y tecnología del color en el extremo sur de Chile. Magallania, 39(1), 193210.

Weissner, P. (1983). Style and social information in Kalahari San projectile points. American Antiquity, 48(2), 253276.

Wiessner, P. (1985). Style or isochrestic variation? A reply to Sackett. American Antiquity, 50(1), 160-166.

Wobst, H. M. (1977). Stylistic behavior and information exchange. University of Michigan Museum of Anthropology, Anthropological Paper, 61(3), 17-42. 